\title{
Surgical Interventions on the External Female Genitalia in Switzerland
}

\section{Chirurgische Eingriffe am äußeren weiblichen Genitale in der Schweiz}

Authors

Affiliations
R. E. Umbricht-Sprüngli ${ }^{1 *}$, M. Gsell ${ }^{2 *}$

${ }^{1}$ Praxis Dr. Umbricht, Zürich, Switzerland

2 Praxis Dr. Gsell, Zürich, Switzerland; Section Gender Studies, Universität Zürich. Asien-Orient-Institut, Zürich, Switzerland

\begin{abstract}
Key words
- female genital plastic surgery

- reduction of labia minora

- aesthetic genital surgery

- functional genital surgery

- age and genital surgery

- motives for female genital surgery

Schlüsselwörter

- weibliche Genitalchirurgie

- äußeres weibliches Genitale

- Intimchirurgie

- Schamlippenverkleinerung

- ästhetische Genitalchirurgie

- funkionelle Genitalchirurgie

- Alter und Genitalchirurgie

- Motive für Genitalchirurgie
\end{abstract}

Deutsche Version unter: www.thieme-connect.de/ ejournals/gebfra

$\begin{array}{ll}\text { received } & 5.8 .2015 \\ \text { revised } & 11.12 .2015 \\ \text { accepted } & 12.12 .2015\end{array}$

Bibliography

Dol http://dx.doi.org/

10.1055/s-0041-111171

Geburtsh Frauenheilk 2016; 76:

396-402 ๔ Georg Thieme

Verlag KG Stuttgart - New York .

ISSN 0016-5751

\section{Correspondence}

Dr. med. Regula Elisabeth

Umbricht-Sprüngli

Praxis Dr. Umbricht

Aurorastrasse 40

8032 Zürich

Switzerland

regula.umbricht@gmail.com

Dr. phil. Monika Gsell

Rämistrasse 59

8001 Zürich

Switzerland

monika.gsell@uzh.ch

\section{Abstract}

Introduction: With this online survey, data on surgical interventions on the external female genitalia in Switzerland, differentiated according to functional, aesthetic and psychological reasons, were collected for the first time.

Materials and Methods: In September 2013 an invitation to respond to the quantitative and qualitative questions of a comprehensive, anonymous online survey was sent by e-mail to a total of 1740 members of the Swiss Society of Gynaecology and Obstetrics (Schweizerische Gesellschaft für Gynäkologie und Geburtshilfe) and the Swiss Society of Plastic Surgery (Schweizerische Gesellschaft für Plastische Chirurgie). Follow-up enquiries were made in June 2014.

Results: By far the most frequently requested intervention was, as expected, reduction of the labia minora. The numbers of this operation had increased significantly between 1992 and 2012 $(p=0.003)$. Reduction of the labia minora for functional reasons decreased continuously in this period (from 50 to $40 \%$ ) while interventions for aesthetic reasons increased continuously (from 20 to $40 \%$ ). The proportion of interventions for psychological reasons remained surprisingly low during the entire investigated period of time (highest value in 2012 of $3.5 \%$ ). Evaluation of the quantitative results on the most frequently stated aesthetic, functional and psychological reasons, however, revealed a high overlap especially in the field of aesthetic and psychological reasons. This overlap points to considerable uncertainties in the medical indications for treatment.

Conclusion: The most interesting results of this study concerns the empirical evidence that it is often difficult in clinical routine to come to a clear aesthetic, functional or psychological indication

\section{Zusammenfassung \\ $\nabla$}

Einleitung: Mit dieser Online-Umfrage wurden erstmals Daten zu chirurgischen Eingriffen am äußeren weiblichen Genitale in der Schweiz erhoben. Dabei fand eine Differenzierung nach funktionellen, ästhetischen und psychologischen Gründen statt.

Material und Methoden: Im September 2013 wurde an die insges. 1740 Mitglieder der Schweizerischen Gesellschaft für Gynäkologie und Geburtshilfe und der Schweizerischen Gesellschaft für Plastische Chirurgie per E-Mail eine Einladung zur Beantwortung der, quantitative und qualitative Fragen umfassenden, anonymisierten OnlineUmfrage verschickt. Nachgefasst wurde im Juni 2014.

Ergebnisse: Der mit Abstand am meisten nachgefragte Eingriff betrifft erwartungsgemäß die Reduktion der inneren Schamlippen. Dieser Eingriff hat zwischen 1992 und 2012 signifikant zugenommen ( $p=0,003)$. Die funktionell begründeten Reduktionen der inneren Schamlippen nahmen in dieser Zeit kontinuierlich ab (von 50 auf $40 \%$ ), die ästhetisch begründeten Eingriffe kontinuierlich zu (von 20 auf 40\%). Der Anteil an psychologisch begründeten Eingriffen bleibt während der ganzen erhobenen Zeitspanne erstaunlich tief (Höchstwert 2012 3,5\%). Die Auswertung der qualitativen Angaben zu den am meisten genannten ästhetischen, funktionellen und psychologischen Gründen zeigt jedoch eine große Überschneidung vor allem im Bereich der ästhetischen und psychologischen Gründe. Diese Überschneidung verweist auf erhebliche Unklarheiten im Bereich der Indikationsstellung.

Schlussfolgerung: Das interessanteste Resultat der Studie betrifft die empirischen Hinweise darauf, dass sich eine klare ästhetische, funktionelle 
and thus there is a need for an instrument to facilitate and improve the indication-making process. oder psychologische Indikationsstellung im klinischen Alltag oft als schwierig erweist und es einen Bedarf an Instrumenten gibt, welche die Indikationsstellung erleichtern und verbessern helfen.

\section{Introduction}

Public media and specialist journals time and again contain reports on a drastic increase in the number of interventions on the female external genitalia for primarily aesthetic reasons. The gynaecological professional societies have expressed their concern about this tendency within the "lifestyle" medical sector and have introduced guidelines for quality assurance [1-4]. Especially noticeable is the flood of statements from the fields of cultural studies and social sciences that critically discuss the trends in cosmetic genital surgery as an effect of a new, media-propagated ideal of beauty [5-10]. Against the background of our own specialist experience, we consider the concern justified that ideals of beauty that are propagated by media may have a normalizing effect on the subjective experience of one's own body $[11,12]$. Even so, in our opinion, explanations that attribute the aestheticisation of the female genitalia exclusively to cultural reasons are not far-reaching enough. One must at least take a complex interaction between cultural, social and psychological factors into consideration $[13,14]$. In addition, we believe that the strongly moralising and condemning statements against cosmetic surgical trends are of little help in understanding not only the situation of the respective patient but also that of the involved physician.

Thus, the indication is in the centre of our attention and interest. In our opinion it is essential to respect the psychological stress of the girls and women who want to undergo an operation of their external genitalia and to meticulously examine when such a surgical intervention is reasonable and whether or not rather psychotherapeutic measures are indicated. On the other hand, the situation of the involved physician who is confronted with the psychological stress of his/her patient must also be considered seriously.

Surprisingly, few data are available in spite of the frequent reports on the drastic increases in the number of interventions on the female external genitalia for primarily aesthetic motivations. We found only one comparable study in the English and German language literature. This was a study on the number of labia minora reductions carried out by the National Health Service (NHS) in England. These figures show that the number of interventions doubled from 380 to 700 cases between 1998 and 2004 [15]. We could not find any other studies that confirm these numbers, that differentiate between functional, aesthetic and psychological indications, that include age distributions or that take the courses of this type of operation into consideration [16-20].

Against the background we conducted an online survey among gynecologist and plastic surgeons in Switzerland a) to test the hypothesis of a significant increase in aesthetic genital surgery in Switzerland and b) to find out how reasons for these interventions may have changed over the last 20 years.

\section{Materials and Methods}

$\nabla$

In September 2013, 1740 anonymised questionnaires were sent by e-mail to the members of the Swiss Society of Gynaecology and Obstetrics and of the Swiss Society for Plastic, Reconstructive and Aesthetic Surgery. The questions were translated into French for the French-speaking part of Switzerland. The questionnaire was sent out again in June 2014.

\section{Construction of the questionnaire}

At the beginning of the questionnaire, there was a short introduction on the topic and confirmation that the survey was supported by the Swiss Society for Plastic, Reconstructive and Aesthetic Surgery and the Swiss Society of Gynaecology and Obstetrics. This was followed by the individual questions that could by answered by stating figures or giving written comments.

\section{Frequency of interventions on the external genitalia}

The first question addressed the frequency of operations on the female external genitalia and, in particular, reduction of the labia minor in the years 2012, 2011, 2010, 2009, 2008 and 2002. The data for the various time periods were compared and statistically evaluated.

\section{Reasons for reduction of the labia minora}

Another question was which percentages of these patients underwent the operation for aesthetic, functional or psychological reasons in the various time periods (1992, 2002, 2008-2012). The figures were evaluated statistically and the content descriptions were pooled.

\section{Complications and patient satisfaction}

With the next question we wanted to know which percentage of patients suffered from complications after reduction of the labia minora and how many patients were not satisfied with the outcome.

\section{Age groups}

How the operated patients were distributed in age groups (less than 16 years, 16 to 25 years, 26 to 50 years, and more than 50 years) and whether increases or decreases were seen in these age groups were dealt with in the next question.

\section{Rare interventions on the female external genitalia}

Further questions concerned the frequencies as well as increase or decrease in numbers of enlargements of the labia majora and labia minora, reduction of the introitus of the vagina, repositioning of the clitoris and reconstruction of the hymen. Because of the very low numbers the results could only be treated descriptively.

\section{Need for guidelines and advanced training courses} Questions about the need for guidelines and advanced training courses completed the questionnaire.

\section{Figures of Santé Suisse}

\section{(Swiss Association of Health Insurances)}

In a second step we acquired and statistically evaluated data on intimate surgical interventions paid for by the Swiss health insurances. 


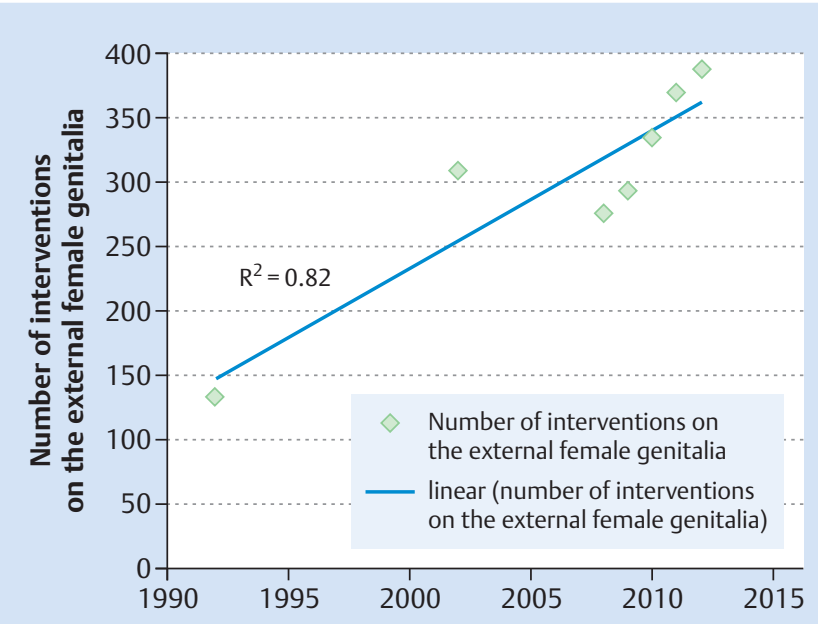

Fig. 1 Regression analysis for the total number of interventions on the external female genitalia for the three investigated time periods (1992, 2002, 2008-2012).

\section{Statistics}

Statistical testing was performed with the help of SPSS 22 under Windows 7 Professional, Service Pack 1. Regression analyses were carried out with the help of Microsoft Excel 2010.

\section{Results}

$\nabla$

A total of 1740 questionnaires were sent out. Of these 272 could be processed and statistically evaluated. Fifteen percent of the gynaecologists (240 of 1600 ) and $23 \%$ of the plastic surgeons (32 of 140) replied. Of the gynaecologists who responded, $37.5 \%$ performed operations of the external female genitalia. Of the responding plastic surgeons, all of them performed these operations. Only $15 \%$ of the responders have been performing these operations for more than 20 years.

Although the response rate for the questionnaire was not high, statistically significant data could be obtained.

\section{Frequency of surgical interventions on the external} female genitalia between 1992 and 2012

The questionnaire revealed that the number of interventions had indeed increased significantly between 1992 and 2012 and almost tripled: on average this is an increase of 11 operations per year. If we consider only the past five years (2008-2012) the rates with 30 operations per year have again increased markedly. Thus, the hypothesis of a strong increase is unequivocally confirmed (O Fig. 1).

Also, the assumption that these interventions were principally concerned with reduction of the labia minora could be clearly confirmed. According to the regression analysis, the number of reductions of the labia minora increased significantly on average by 9 operations per year between 1992 and 2012 (p-value = 0.003 ). If we consider only the years $2008-2012$, there is an average increase of 30 operations per year: $\mathrm{p}$-value $=0.001$ ( $\odot$ Fig. 2 ).

\section{Reasons for reduction of the labia minora}

In accord with our hypothesis, we expected that the increase in the field of labia reductions would mainly be due to aesthetic or,

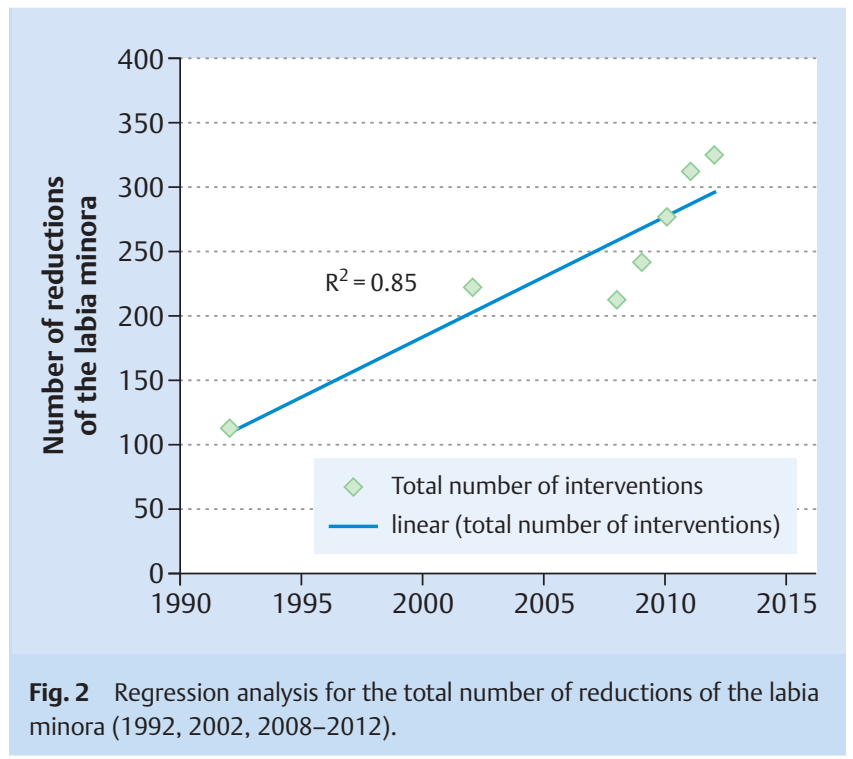

respectively, cosmetic reasons. We thus asked the participants in the survey to state their estimates as to what percentages of the operations that they had performed were motivated by a) aesthetic, b) functional, c) aesthetic and functional, as well as d) psychological aspects and to what extent the relationship between these reasons had changed numerically between 1992 and 2012. Evaluation of the data confirmed our hypothesis ( $\mathbf{O F i g . ~ 3 ) .}$ Aesthetic reasons have increased continuously since1992, in the same period functional reasons have decreased continuously. Psychological reasons were given for a surprisingly small number of interventions: the figures here lie in the region of $1-2 \%$, since 2002 with a minimally increasing tendency up to $3.5 \%$ in 2012 .

If we consider only the answers of the physicians who perform 10 or more such interventions per year, an even more marked increase in the number of aesthetic operations in comparison with functional operations is apparent (O Fig. 4).

The question about the most frequently mentioned aesthetic, functional and psychological reasons yielded the following answers: by far the most frequently stated aesthetic reason was based on the visibility and protrusion of the labia minora (29 responses); equally often mentioned were displeasure not further specified and specific feelings of disgust and shame (15 responses). Further reasons mentioned were asymmetry (11 responses) and rejection (4 responses). Among the functional reasons, complaints during sport activities were mentioned most frequently (altogether 86 responses: cycling $50 \times$, general sports $21 \times$, riding $15 \times$ ). Other frequently mentioned functional reasons concerned complaints and pain during sexual intercourse (35 responses) as well as entrapment and friction soreness while sitting and walking (30 responses). Complaints about urination were mentioned twice and complications after an aesthetic operation and recurrent bladder infections were mentioned once each. The most frequently stated psychological reasons were: impairments of self-confidence and well-being with one's own body $(10 \times)$, feeling of abnormality $(6 \times)$, shame $(5 \times)$, sexual inhibition $(3 \times)$, and rejection by the partner $(2 \times)$. For the latter reason, in one of the two cases. the patient was informed that the operation could not be carried out. In a further answer, the individual patient was informed that no operation could be per- 


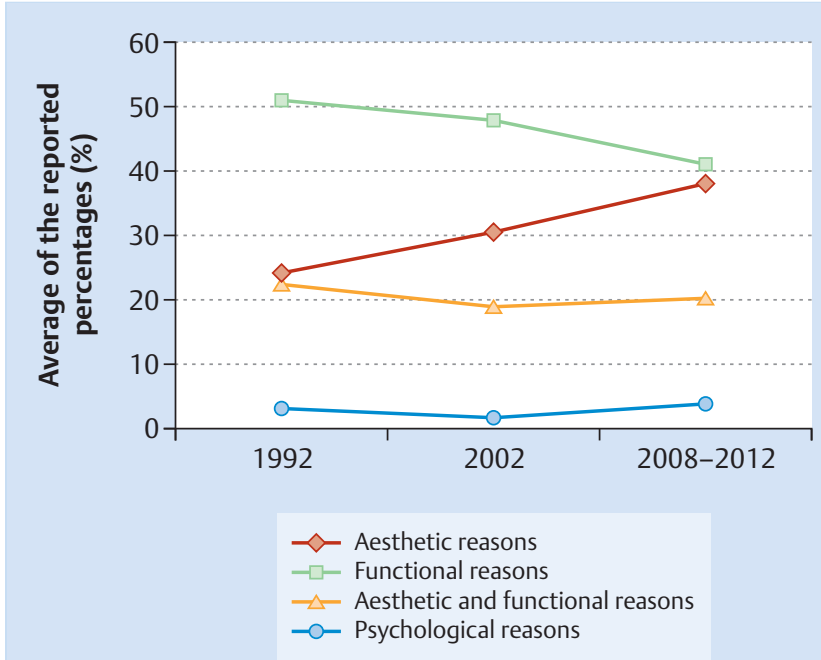

Fig. 3 Changes of the reasons over the last 20 years (average percentage values in the years1992, 2002, 2008-2012).

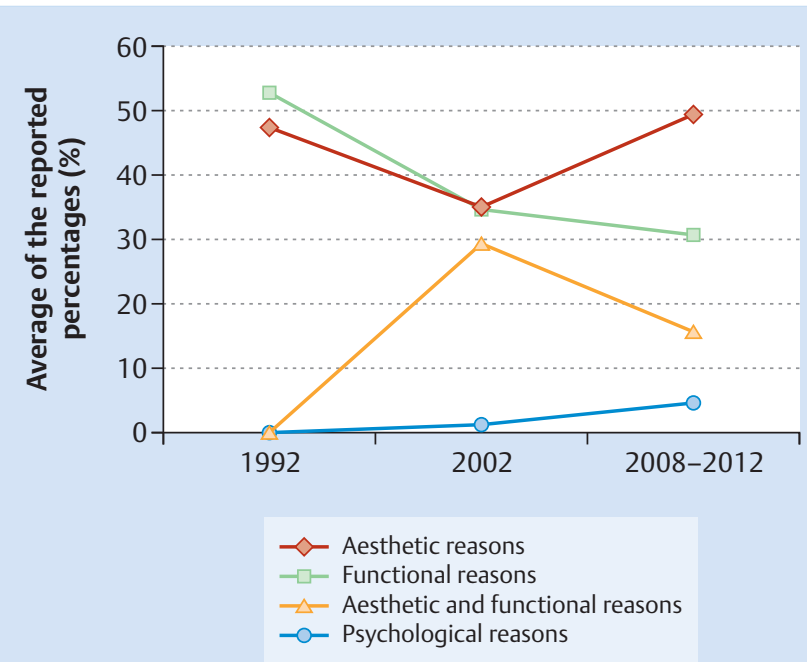

Fig. 4 Changes of the reasons given over the last 20 years to 24 surgeons performing 10 or more operations per year.

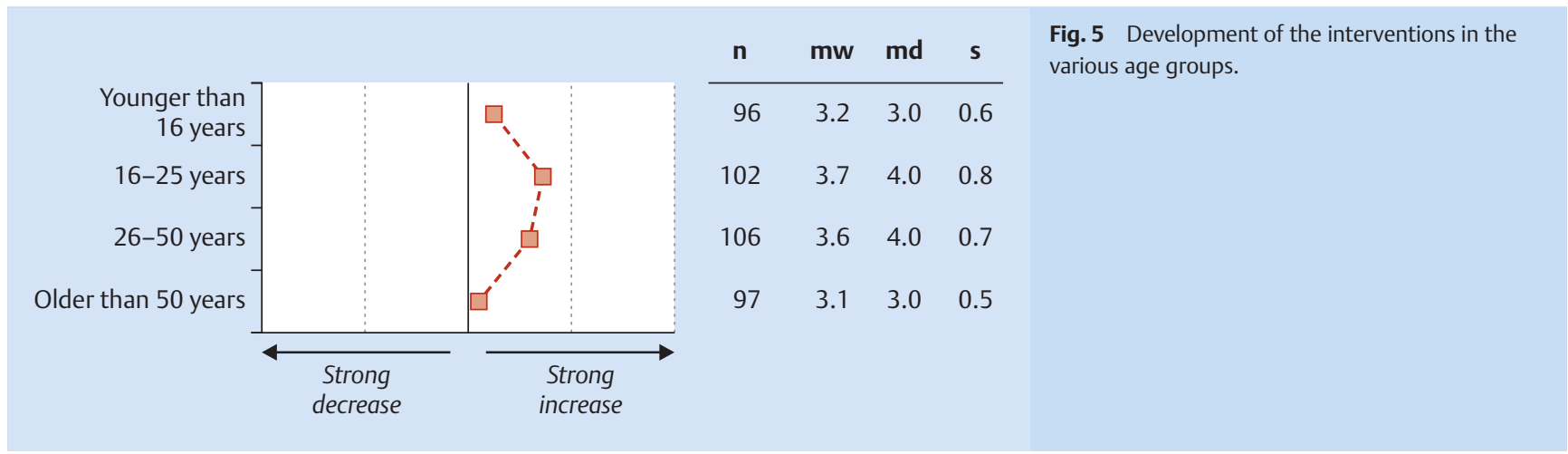

formed for purely psychological reasons. In two cases the respective patients were informed that the mental stress could be attributed to functional problems. In all other cases, strictly speaking, it remains open whether or not a surgical intervention was indicated and undertaken on account of the stated reasons.

\section{Age distribution}

With regard to the age structure, we firstly wanted to find out in which age group the operation was performed most frequently and, secondly, how the interventions had developed in the various age groups. The figures clearly show that the 26- to 50-yearold patients form the largest group (92 responses, on average $54 \%$ of the patients in this age group); the 16 to 25 year olds constitute the second largest group (81 responses, on average $39.3 \%$ of the patents in this age group). In the youngest age group there are very few patients: one participant each reported that 1 or, respectively, 2 of their patients were in this age group; 2 participants reported that $10 \%$ of their patients were younger than 16 years old ( Fig. 5 ). In all four age groups a more or less strong upwards tendency was observed.

\section{Complications and patient satisfaction}

The question as to the percentage of performed operations that were accompanied by complications was answered by 106 par- ticipants. On average complications occurred in $5.75 \%$ of the cases. The responses ranged from 1 to $50 \%$ complications, where a review at the raw data shows that those who reported complications in $50 \%$ of the interventions had effectively only performed a handful of operations. If we considered only the answers of the 27 participants who performed 10 or more procedures per year we come to an average of $7.3 \%$ complications.

The following complications were reported: problems of woundhealing (40 nominations), haematomas (17 nominations) and infections (5 nominations). Pain, swelling, problems during intercourse, too much or too little resection, defects in the labia, formation of holes in the labia minora, perforation of the hymen as well as a postoperative asymmetry were reported once each.

106 participants answered the question concerning patient satisfaction and dissatisfaction. The evaluation revealed that $94 \%$ of the patients were satisfied. If we consider again only the answers of the 27 surgeons with the largest case numbers, the result is not as good with $9 \%$ unsatisfied patients and $91 \%$ satisfied patients. The summary of the reasons for dissatisfaction reveals that these often cannot be clearly differentiated from the complications. Thus as reasons for patient dissatisfaction were mentioned: Labia minora too large or too small (22 nominations), results that did not conform to the desired outcome (15 nominations), scars or wound-healing problems (13 nominations), asymmetry (6 nom- 
inations), residual pain (1 nomination), complaints (2 nominations), pain during sexual intercourse (2 nominations), irregularities ( 2 nominations), surgically not reparable, subjectively disturbing tissue consistency and colour (1 nomination), not surgically changed height and visible position of the clitoris with foreskin (1 nomination) and excessively long duration of convalescence (1 nomination) were reported as reasons for patient dissatisfaction.

\section{Rare interventions in the region}

\section{of the female genitalia}

Enlargement of the labia majora or labia minora, reduction of vaginal introitus, repositioning of the clitoris, resection or cleavage of the clitoris foreskin or hymen reconstruction are operations rarely performed and have neither increased nor decreased in the past years.

\section{Opportunities for advanced training} and material for patient counselling

$47.3 \%$ of all participants wished for advanced training opportunities, $60 \%$ for information material suitable for patient counselling, $68 \%$ wished for more intensive education of young women about the inter-individual variability of the external female genitalia and $45 \%$ for a list of sexual therapists or psychotherapists specialised in the management of patients with excessive genital shame.

\section{Referral of patients to participate in qualitative discussions}

$31 \%$ of the participants declared their willingness to refer patients to a qualitative interview.

Figures from the Swiss Health Insurance Association

Comparable to our survey are the figures on the resection of hypertrophic labia minora from the Swiss Association of Health Insurances (Santé Suisse). According to the regression analysis, the number of reported resections of hypertrophic labia minora rose by about 6 interventions per year. This increase is not statistically significant ( $p$ values $=0.079>0.05$ ), but shows a tendency similar to that of our data for all surgeons in the period 2002-2012 (O Fig. 6).

\section{Discussion \\ $\nabla$}

The results of this online survey confirm the hypothesis of an increase in surgical reductions of the labia minora over the past 20 years. The rate of increase was markedly higher in the years 2008-2012.

On average, interventions for aesthetic reasons increased and those for functional reasons decreased similarly between 1992 and 2012, i.e., the functional reasons decreased continuously while the aesthetic reasons increased steadily. If the details from those surgeons who operate more frequently are taken separately, the picture changes somewhat: operations for aesthetic reasons and those for functional reasons ran more or less in parallel between 1992 and 2002 whereas they diverged more and more between 2002 and 2012: operations for aesthetic reasons now increased conspicuously and significantly in comparison to those for functional reasons.

The data on operations for psychological reasons gave surprisingly low numbers. In general, one assumes that $20 \%$ of cosmetic

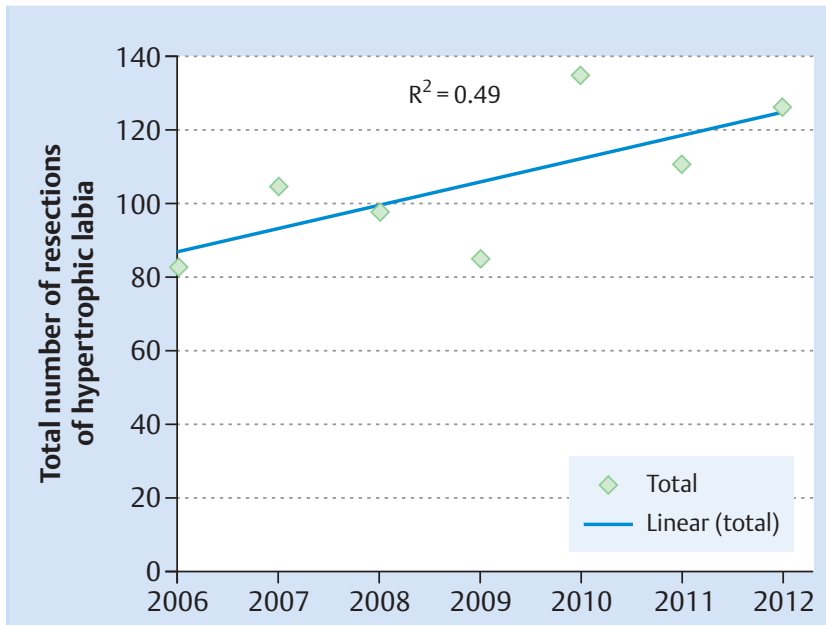

Fig. 6 Statistically not significant increases in the number of resections of hypertrophic labia minora for functional reasons according to health insurance figures for the years 2006-2012.

operations are based on psychological reasons [23]; however, in our survey in only $3.5 \%$ were such reasons given.

The increase in labia minora reductions involves mostly patients in the age groups of 26 - to 50 -years and 16 - to 25 -years old. If we compare this with the increasing number of younger patients who have undergone breast augmentations in the past 20 years, we must also assume an increase in intimate surgical interventions among younger women. Operations in girls under age of 16 and even children are mentioned sporadically in our study and the literature [21,22]. In Switzerland, operations on patients under 18 years of age require the written consent of the parents or guardians.

The reported complication rate amounted to an overall average of $5.75 \%$. Ninety-four percent of the patients were satisfied with the outcome according to estimations of the surgeons, $6 \%$ were not satisfied. If the figures for the group of surgeons who performed more operations are assessed separately, there is a somewhat higher rate of complications with an average of 7.3 and $9 \%$ unsatisfied patients. If we compare these results with the corresponding figures in the literature, ours are seen to be somewhat higher $[16,18,19]$. This difference can possibly be explained by the fact that our data were acquired anonymously and may thus reflect a more realistic view of the actual situation. If we compare the written descriptions of the complications and the reasons for dissatisfaction, we see that these two categories are closely related to each other.

The most interesting result of this study concerns the description of the reasons for reduction of the labia minora: if we compare the answers about the most frequent functional, aesthetic and psychological reasons we see some conspicuous overlaps: feelings of shame and revulsion as well as feelings of abnormality are mentioned both in the categories of aesthetic and of psychological reasons, as are anxiety of rejection by the partner and actual rejection by the partner. Similarly, in the group of functional reasons we find answers that are suggestive of uncertainty about the indication. Thus an explanation is required as to why a labia reduction should be indicated for painful sexual intercourse or recurrent bladder infections. 
We suspect that there are objective reasons for the difficulties in distinguishing between functional, aesthetic and psychological reasons for a surgical intervention. A possible reason could be that the desire for a labioplasty is a frequent expression of unconscious conflicts. By "unconscious" we mean that the patient is not consciously aware of the conflicts and, as a result, they cannot be expressed by the patient nor recognised by the examining physician. Accordingly, aesthetic dissatisfaction with the appearance of one's own genitalia can be an expression of a maturation conflict and, for example, be indicative of an insufficient integration of sexual function into the unconscious body image. Of this inner struggle, merely an uneasiness about one's own genitalia is accessible to consciousness. The genitalia are then perceived as repulsive (aesthetic reason), bothersome (functional reason) and inhibiting (manifest psychological reason). The patient does not "know" anything about the underlying, unconscious conflicts and therefore cannot describe them. Our finding that uncertainty exists about what qualifies as functional, aesthetic or psychological reasons may suggest that an in-depth exploration is indicated.

The guidelines and recommendations on aesthetic genital surgery approved by the various gynaecological professional societies point in the same direction [1-4]. Common to all is that they recommend or even demand a comprehensive psychological assessment for all medically not indicated interventions and quite rightly point out that in cases of pre-existing mental disorders there is a high risk that the operation may do more harm than good (see also [12,24]).

However, the presumably low evidence level must be taken into consideration not only for the current indication practice but also with regard to the recommendations formulated in the guidelines [25]. Long-term studies on the psychosocial effects of labia reduction are not available. As yet there is no evidence that a reduction of the labia minora leads to a persisting improvement in mental well-being - irrespective of whether the operation was performed for a functional, aesthetic or psychological indication. Conversely, to the best of our knowledge, there are no studies on the effects of routine psychological assessment for patients who wish for a labioplasty. Also, we know from other specialties that such routine assessments can unnecessarily lengthen the period of psychological stress (e.g., in certain cases of transsexualism) or that they are considered by the patient as well as the physician simply as pro forma activities, which accordingly can contribute little to the clarification of unconscious conflicts. Finally, there is only little evidence that the recommendations formulated in the guidelines are suitable as instruments for quality assurance in clinical routine and are able to significantly improve assessment and indication. In addition, many physicians may find it difficult to refer their patients to a psychological assessment or to conduct it themselves. In contrast, what would be really helpful in clinical routine and what is actually wished for by over $60 \%$ of the participants in our survey is information material suitable for the counselling of those patients who want to undergo labioplasty. The results of our study suggest that this information should not only fulfil the task of explaining to patients the inter-individual variation in appearance of the female genitalia. They should be conceived in a way to allow room to express ambivalence, conflict and uncertainty during the counselling session on part of both the patient and the physician. This would allow the counselling physician to take seriously the patient's psychological stress and thus the accompanying desire for a surgical intervention without being under pressure to fulfil the wish immediately. In some cases, the course of such a counselling could provide an indication for further psychodynamic assessment, in other cases the indication for a surgical intervention.

\section{Practical Conclusions \\ $\nabla$}

The evaluation of our survey reveals that the number of reductions of the labia minora for aesthetic reasons is increasing. However, the descriptions of the aesthetic, functional and psychological reasons show how difficult it is in clinical routine to clearly differentiate them from each other. A simple measure to improve the indication could be the development of counselling material that would help open and deepen the conversations between the responsible physician and the respective patient.

\section{Acknowledgements}

We thank the Swiss Society of Plastic, Reconstructive and Aesthetic Surgery (Schweizerische Gesellschaft für Plastische, Rekonstruktive und Ästhetische Chirurgie), the Swiss Society of Gynaecology and Obstetrics (Schweizerische Gesellschaft für Gynäkologie und Geburtshilfe) and the Department of Gender Studies of Zurich University (Fachbereich Gender Studies der Universität Zürich) for their support of this survey. We are grateful to Dr. med Judith Pok for fruitful discussion during the conception of the questionnaire, Anita Holdener for the technical realisation, Dr. Martina Leonarz for productive feedback on an earlier version of this manuscript and Dr. med. Daniel Umbricht for his help with the statistical evaluation of the data as well as the correction of the english paper.

\section{Conflict of Interest \\ $\nabla$}

None.

\section{References}

1 The American College of Obstetricians and Gynaecologists. ACOG Committee Opinion (2007) Vaginal "rejuvenation" and cosmetic vaginal procedures. ACOG Committee Opinion; number 378 (vol 110, no.3). Washington, DC

2 Stellungnahme der Deutschen Gesellschaft für Gynäkologie und Geburtshilfe zur Intimchirurgie. Geschäftsstelle der Deutschen Gesellschaft für Gynäkologie und Geburtshilfe e.V. Robert-Koch-Platz 7, 10115 Berlin. Berlin.13.Juli 2009. Online: https://www.klinikum. uni-heidelberg.de/fileadmin/pressestelle/PK/Stellungnahme_ Intimchirurgie.pdf; last access: 12.03.2016

3 Konsensus Papier der Österreichischen Gesellschaft für Gynäkologie und Geburtshilfe. Online: http://www.frauengesundheit-wien.at; last access: 09.03.2010

4 Wyss P, Pok J, Hagmann P et al. Expertenbrief No.39. der Schweizerischen Gesellschaft für Gynäkologie und Geburtshilfe. Kommission Qualitätssicherung. Nicht medizinisch indizierte vulvo-vaginale Eingriffe. Online: http://www.sggg.ch/fileadmin/user_upload/Dokumente /3_Fachinformationen/1_Expertenbriefe/De/39_Nicht-medizinisch_ indizierte_vulvo-vaginale_Eingriffe_2011.pdf; last access: 17.03.2016

5 Moran C, Lee C. What's normal? Influencing women's perceptions of normal genitalia: an experiment involving exposure to modified and nonmodified images. BJOG 2014; 121: 761-766

$6 \mathrm{McDougall} \mathrm{LJ}$. Towards a clean slit: how medicine and notions of normality are shaping female genital aesthetics. Cult Health Sex 2013; 15: 774-787

7 Ashong AC, Batta HE. Sensationalising the female pudenda: an examination of pubic communication of aesthetic genital surgery. Glob J Health Sci 2012; 5: 153-165 
8 Lloyd J, Crouch NS, Minto CL et al. Female genital appearance: "Normality" unfolds. BJOG 2005; 112: 643-646

9 Placik OJ, Arkins JP. Plastic surgery trends parallel Playboy magazine: the pudenda preoccupation. Aesthet Surg J 2014; 34: 1083-1090

10 Wolf $N$. The Beauty Myth: how Images of Beauty are used against Women. New York: William Morrow; 1991

11 Gsell M. Die Bedeutung der Baubo. Kulturgeschichtliche Studien zur Repräsentation des weiblichen Genitales. Frankfurt am Main: Stroemfeld; 2001

12 Umbricht R, Umbricht T. Psychoanalyse und Plastische Chirurgie: Der Körper als Verwandlungsobjekt. Zur Psychodynamik schönheitschirurgischer Eingriffe. In: Böker H, Hrsg. Psychoanalyse im Dialog mit den Nachbarwissenschaften. Giessen: Psychosozialverlag; 2010: 301322

13 Hirsch M. Körperinszenierungen. Über Parallelen des Körperagierens bei den „Naturvölkern“, zeitgenössischen Jugendlichen und pathologischen Formen. Forum der Psychoanalyse 2004; 4: 367-378

14 Salecl R. (Per)Versionen von Liebe und Hass. Berlin: Volk \& Welt; 2000: 187-220

15 Lih Mei Liao S, Creighton M. Request for cosmetic genitoplasty: how should healthcare providers respond? BMJ 2007; 334: 1090-1092

16 Rouzier R, Louis-Sylvestre C, Paniel BJ et al. Hypertrophy of labia minora: experience with 163 reductions. Am J Obstet Gynecol 2000; 182 (1 Pt 1): $35-40$
17 Borkenhagen A, Kentenich H. Labienreduktion - Neuester Trend der kosmetischen Genitalkorrektur - Übersichtsarbeit. Geburtsh Frauenheilk 2009; 69: 19-23

18 Goodman MP, Placik OJ, Benson RH 3rd et al. A large multicenter outcome study of female genital plastic surgery. J Sex Med 2010; 7 (4 Pt 1): $1565-1577$

19 Goodman MP. Female genital cosmetic and plastic surgery: a review. J Sex Med 2011; 8: 1813-1825

20 Ostrzenski A. Cosmetic gynecology in the view of evidence-based medicine and ACOG recommendations: a review. Arch Gynecol Obstet 2011; 284: 617-630

21 Jothilakshmi PK, Salvi NR, Hayden BE et al. Labial reduction in adolescent population-a case series study. J Pediatr Adolesc Gynecol 2009; 22: 53-55

22 Lynch A, Marulaiah M, Samarakkody U. Reduction labioplasty in adolescents. J Pediatr Adolesc Gynecol 2008; 21: 147-149

23 Vargel S, Uluşahin A. Psychopathology and body image in cosmetic surgery patients. Aesthetic Plast Surg 2001; 25: 474-478

24 Barbara G, Facchin F, Meschia M et al. "The first cut is the deepest": a psychological, sexological and gynaecological perspective on female genital cosmetic surgery. Acta Obstet Gynecol Scand 2015; 94: 915920

25 Ostrzenski A. Selecting aesthetic gynecologic procedures for plastic surgeons: a review of target methodology. Aesthetic Plast Surg 2013; 37: $256-265$ 